\title{
Spreading Word-Of-Mouth when Loving and Hating the Same Object: The Impact of Attitude Ambivalence on Pre- and Post-Failure Word-Of-Mouth
}

\author{
Nico Heuvinck ${ }^{1}$ \\ Yves Van Vaerenbergh ${ }^{2}$ \\ Iris Vermeir ${ }^{3}$ \\ Maggie Geuens ${ }^{4}$
}

\begin{abstract}
Short Abstract
This paper presents four studies investigating the impact of attitudinal ambivalence - and different types of ambivalence based on the type of underlying conflicting reactions; manifest and anticipated ambivalence - on positive and negative word-of-mouth (WOM). Results of Study

1 and 2 indicate that manifest ambivalent respondents spread more negative and less positive WOM compared to anticipated ambivalent and univalent respondents. Study 3 and 4 show that the impact of a product failure in terms of spreading positive and negative WOM is larger for respondents holding univalent or anticipated ambivalent attitudes than for manifest ambivalent respondents.
\end{abstract}

Key words: word-of-mouth, attitudes, ambivalence

\footnotetext{
${ }^{1}$ Contact author: PhD student at University College Ghent, Faculty of Business Administration and Management, Department of Marketing, Schoonmeersstraat 52, B-9000 Ghent, Belgium \& Ghent University, Faculty of Economics and Business Administration, Department of Marketing, Tweekerkenstraat 2, B-9000 Ghent, Belgium, Tel (direct) +32 9 2432473,Tel (mobile) +32 473 479957, E-mail nico.heuvinck@ hogent.be

${ }^{2} \mathrm{PhD}$ student at University College Ghent, Faculty of Business Administration and Management, Department of Marketing, Schoonmeersstraat 52, B-9000 Ghent, Belgium \& Ghent University, Faculty of Economics and Business Administration, Department of Marketing, Tweekerkenstraat 2, B-9000 Ghent, Belgium

${ }^{3}$ Professor of Marketing at University College Ghent, Faculty of Business Administration and Management, Department of Marketing, Schoonmeersstraat 52, B-9000 Ghent, Belgium \& Ghent University, Faculty of Economics and Business Administration, Department of Marketing, Tweekerkenstraat 2, B-9000 Ghent, Belgium

${ }^{4}$ Professor of Marketing at Ghent University, Faculty of Economics and Business Administration, Department of Marketing, Tweekerkenstraat 2, B-9000 Ghent, Belgium
} 


\section{Extended Abstract}

Imagine you have simultaneously positive and negative thoughts and feelings about the new iPad, a phenomenon that is called (subjective) attitude ambivalence (Kaplan 1972; Otnes et al. 1997). Will you bring up good as well as bad features to others about this product compared to when you are convinced the iPad has no bad features at all (i.e. univalent attitude)? And what happens when your Ipad fails? Four studies were set up to investigate the relationship between spreading positive and negative word-of-mouth (WOM), (different types of) attitude ambivalence and product failure.

In study 1, we asked respondents to rate their subjective ambivalence towards a store chain next to indicating positive and negative WOM. Results show that ambivalent people will spread less positive and more negative WOM than univalent ones.

Study 2 tries to refine the results of Study 1 by taking into account different types of attitudinal ambivalence. Subjective ambivalence can be caused by manifest and/or anticipated conflicting reactions. When an individual is aware of the thoughts and the feelings s/he has about a product that are conflicting with the majority of thoughts and feelings the individual has (i.e., with his/her dominant reactions), these conflicting reactions are called manifest conflicting reactions (Priester et al. 2007). When an individual has few or no deliberate conflicting reactions, s/he can still recognize that conflicting information might exist of which s/he is at present unaware. These conflicting reactions are called anticipated conflicting reactions (Priester et al. 2007). We distinguish two different types of attitudinal ambivalence based on the type of conflicting reactions underlying the subjective ambivalence. We define manifest ambivalence as the ambivalence that is mainly fed by conflicting reactions of which one is aware. When people are unaware of any conflicting reactions, but anticipate that such reactions exist, individuals experience anticipated ambivalence.

To investigate the relationship between the two types of ambivalence and WOM, we manipulated the type of conflicting reactions that cause subjective ambivalence. To this end, we varied the amount of positive and negative attributes respondents received about an MP3-player in a similar way as in Priester et al. (2007), and varied the opinion of one's best friend. Again, we find that positive (negative) WOM corresponds positively (negatively) with respondents' initial attitude, as the latter is more favorable for anticipated ambivalent people compared to manifest ambivalent ones. Results indicate that anticipated ambivalent respondents, despite having the same ambivalence level as manifest ambivalent respondents, engage in more positive and less negative WOM than manifest ambivalent people. The fact that they only anticipate instead of know their conflicting reactions, could explain why they are less inclined to share those negative thoughts with other people. Although the WOM of anticipated ambivalent individuals is more positive than the one of manifest ambivalent individuals, their WOM varies depending on the valence of their dominant reactions. If positives (negatives) are dominant, more (less) positive WOM and less negative (positive) WOM will be spread. In contrast, manifest ambivalent people generally spread more negative than positive WOM. Possibly negative features weigh only more heavily than positive ones, if one is aware of the negative features and not when one anticipates negative features.

Now further imagine that you are ambivalent towards the iPad while one of your friends is convinced it possesses only good features (i.e., univalent attitude). One day, the product breaks 
down. Will your reactions to this failure differ in terms of the WOM you spread? Past research has shown that a failure leads customers to spread less positive and more negative WOM (e.g., Richins, 1983, Von Wangenheim, 2005). In Studies 3 and 4, we investigate the moderating role of attitude ambivalence for the relationship between a product failure and WOM. Previous studies indicate that customers who have a high relationship quality towards a service provider may feel more betrayed when failures occur than customers with low relationship quality. Subsequently, they take more negative actions than customers who have a low relationship quality with a service provider. This is known as the love-becomes-hate effect (Grégoire and Fisher, 2008; Grégoire et al. 2009). If we translate these findings to our research context, they suggest that ambivalent and univalent customers might differ in their reactions to failures. Due to the fact that ambivalent customers know there are both positive and negative features associated with a product (Priester and Petty, 1996), they may be prepared for the fact that a failure once might happen to them. In contrast, univalent customers believe that a product only possesses good features (Priester and Petty, 1996). If a failure does occur, they can be expected to react more intensely because this failure was totally unexpected.

In study 3, we measured consumers' subjective ambivalence towards their MP3-player and next presented a scenario with or without failure (between-subjects design). Results show that following a failure, univalent customers' positive WOM drops significantly, while their negative WOM regarding the product increases. For ambivalent customers, the impact of a product failure is less strong (see Figures below). Our results therefore delineate that customers' reactions to a product failure clearly differ depending on the level of ambivalence they have towards the product.

\section{Positive WOM}

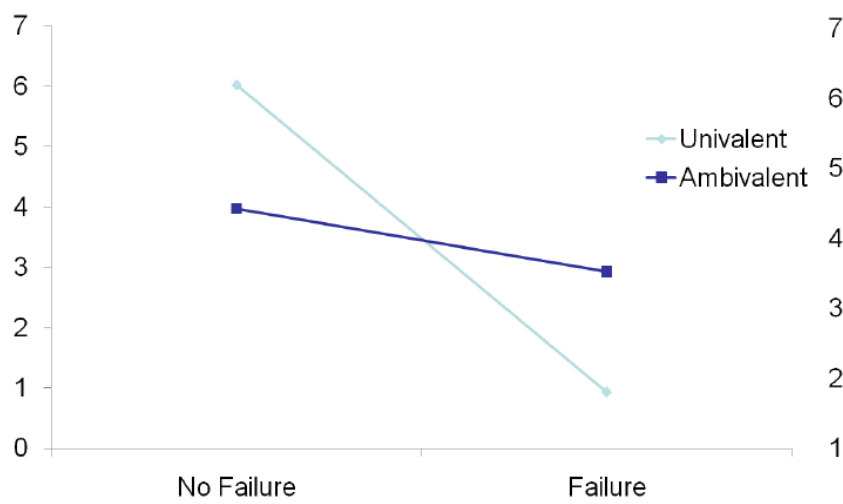

Negative WOM

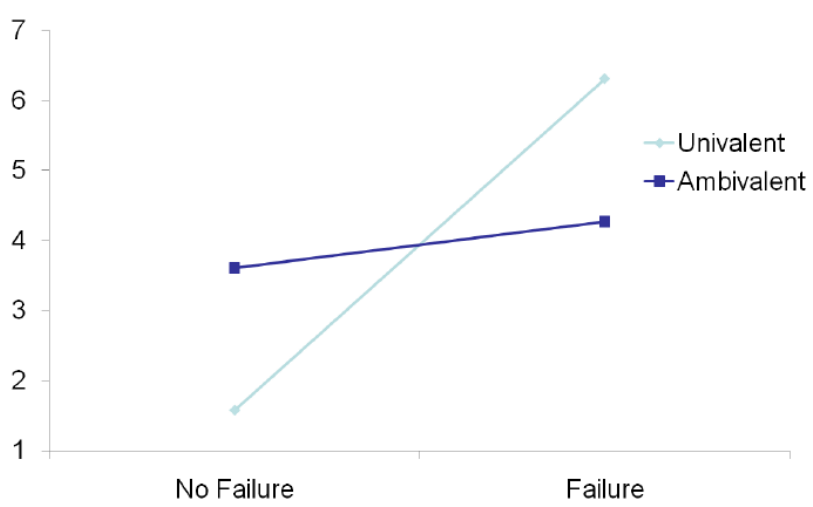

In study 4, we conducted a repeated measures experiment to investigate the moderating role of different types of conflicting reactions underlying subjective ambivalence (anticipated versus manifest ambivalence) on the relationship between a product failure and WOM. We replicate the findings of Study 3 and extend them by indicating that the WOM of univalent and anticipated ambivalent respondents is more strongly influenced by failures compared to the WOM of manifest ambivalent respondents (see Figures below). When anticipated ambivalent individuals are confronted with a failure their negative WOM increases and positive WOM drops tremendously compared to manifest ambivalent people. Interestingly, although anticipated 
ambivalent customers are ambivalent, they seem to react as univalent customers when experiencing a failure.

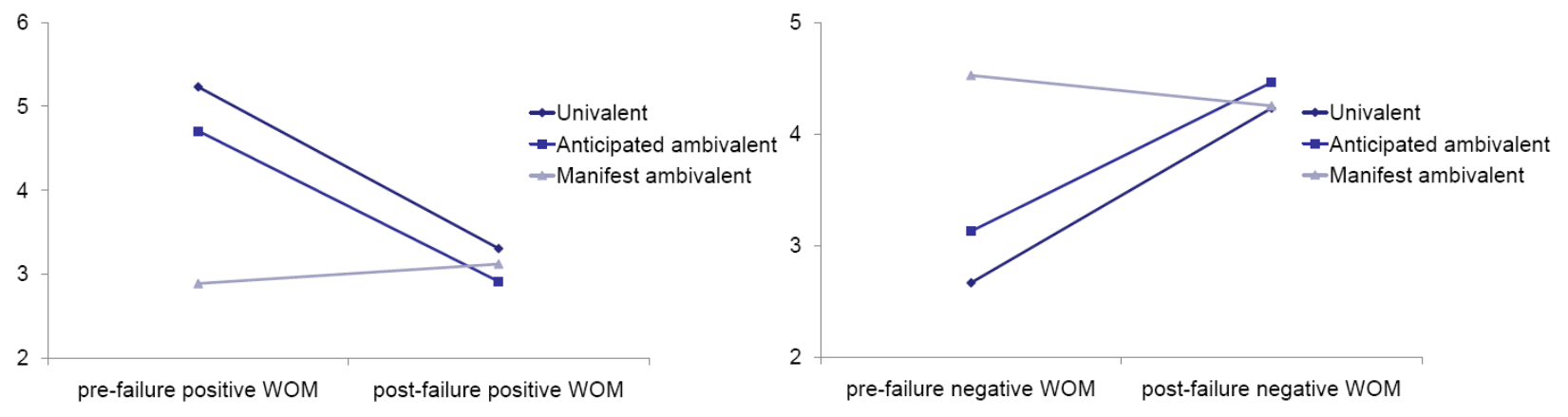




\section{References}

Grégoire, Y. and R.J. Fisher (2008), “Customer Betrayal and Retaliation: When Your Best Customers Become Your Worst Enemies", Journal of the Academy of Marketing Science, 36, 247-61.

Grégoire, Y., Tripp, T.M. and R. Legoux (2009), "When Customer Love Turns into Lasting Hate: The Effects of Relationship Strength and Time on Customer Revenge and Avoidance", Journal of Marketing, 73, 18-32.

Kaplan, K.J. (1972), "On the ambivalence-indifference problem in attitude theory and measurement: A suggested modification of the semantic differential technique", Psychological Bulletin, 77, 361-72.

Otnes, C., Lowrey, T.M. and L.J. Shrum (1997), "Toward an understanding of customer ambivalence", Journal of Consumer Research, 24, 80-93.

Priester, J.R. and R.E. Petty (1996), "The gradual threshold model of ambivalence: Relating the positive and negative bases of attitudes to subjective ambivalence", Journal of Personality and Social Psychology, 71, 431-49.

Priester, J.R., Petty, R.E. and K. Park (2007), "Whence univalent ambivalence? From the anticipation of conflicting reactions", Journal of Consumer Research, 34, 11-21.

Richins, M.L. (1983), "Negative Word-of-Mouth by Dissatisfied Customers: A Pilot Study", Journal of Marketing, 47, 68-78.

Von Wangenheim, F. (2005), "Postswitching Negative Word-of-Mouth", Journal of Service Research, 8, 67-78. 